\title{
SIETE POSTULADOS DEL BIEN COMÚN: UNA INTERPRETACIÓN
}

\author{
SEVEN POSTULATES OF THE COMMONWEALTH: AN INTERPRETATION
}

\author{
DE LA OSSA V. JAIME, Dr. Sci.
}

Editor Revista Colombiana de Ciencias Animal - RECIA Universidad de Sucre, Facultad de Ciencias Agropecuarias, Colombia. Correspondencia: jaimedelaossa@yahoo.com

\begin{abstract}
El bien común es un concepto que en general puede ser entendido como aquello de lo que se benefician todos los ciudadanos o como los sistemas sociales, institucionales y medios socioeconómicos de los cuales todos dependemos, que funcionen de manera que beneficien a toda la gente. El concepto también se puede referir a la conveniencia económica -o bienestar socio-económico y ambiental general de una sociedad o comunidad o la situación que maximiza la suma del beneficio o utilidad de todos y cada uno de los individuos (OSTROM, 2011; FELBER, 2012; http://es.wikipedia.org/wiki/Bien_com\%C3\%BAn).
\end{abstract}

Es claro, como lo afirma FELBER (2012) que el sistema económico mundial viola frontalmente los valores democráticos básicos, asegura que esa violación de los valores democráticos se debe a que el sistema está mal programado y fomenta valores opuestos a los que recogen las Constituciones. Sus apreciaciones van más allá, se puede evidenciar cuando afirma que si vivimos los medios como si fueran los fines se comete un error estratégico, considera como fines: la dignidad humana, la ecología, el reparto justo y el respeto a la democracia y al medio ambiente.

En la actualidad el éxito económico se mide con valores o indicadores monetarios: producto interior bruto, beneficios que dejan fuera a los seres humanos y al medio en el que vivimos. Estos indicadores no nos dicen nada sobre si hay guerra, si se vive en una dictadura, si se sobreexplotan los recursos del medio, etc. De la misma manera una sociedad que tenga beneficios no nos indica nada sobre las condiciones de sus ciudadanos ni sobre lo que produce ni como lo produce. Por su parte, el balance del bien común mide como una sociedad vive: la dignidad humana, la solidaridad, la justicia social, la sostenibilidad ecológica y la democracia con todos sus actores (OSTROM, 2011; FELBER, 2012).

Razón por la cual se plantea, en este escrito, un marco que puntualice, por lo menos, lo más relevante, que como utopía congruente deba impulsarse en nuestro medio y que en tal sentido, sería:

El bien común debe respetar el derecho natural y único que tiene la sociedad de buscar y obtener el bienestar dentro de un proceso de desarrollo que no deteriore la base productiva, al tiempo que busque acrecentar el acceso participativo y activo al sistema, en bien de los ciudadanos actuales y de las generaciones futuras.

El bien común siempre está en construcción, no es un trabajo finalizado, es una obra de edificación social permanente que requiere el concurso general y riguroso de todos los actores de la comunidad. El descuido en el proceso permea la filosofía del sistema y abre vías que pueden generar el caos, degenerando el proceso y ofreciendo a las postre resultados adversos al bien común, situaciones que lo destruyen y lo extinguen.

El bien común es un patrimonio natural de la sociedad, es inalienable, no es negociable ni puede darse como garantía de pago o reconocimiento alguno, de él depende la sobrevivencia exitosa de la sociedad; de las interacciones equilibradas entre el bien común y la sociedad se obtiene la satisfacción armoniosa de las necesidades del desarrollo y la dispersión social del bienestar generalizado. 
El bien común no está atado a privilegios de clase, grupo o condición social, solo se vincula al carácter de ciudadano, a quien se le exige que piense y actúe conscientemente, en cuanto tiene que ver con el valor, conservación y cuidado del bien de común, en razón de los derechos naturales que le pertenecen y de los cuales deriva la naturaleza de su ser.

El bien común no riñe, ni discrimina credos, solo se aparta de las posiciones individuales o grupales que no hacen parte de la matriz de valores éticos colectivos, no desconoce ni retiene beneficios, pero si valora el bienestar general como principio sustantivo del ser integral y su participación como individuo grupal del proceso.

El bien común hace parte del todo, no es excluyente, no posee estructura alguna que desplace el papel que a la comunidad le compete en el cumplimiento social de sus deberes y con ellos el de participación equitativa y compromiso de vigilancia de los valores que le son derivados.

El bien común propende por la conservación activa y participativa del sistema general. Es un sistema que mantiene las interacciones que permiten satisfacer la necesidades del desarrollo en forma equitativa sin deteriorar la base de sus resultados, buscando en cada caso concertar la oferta con las metas y los resultados, dentro de un equilibrado flujo de bienes y servicios.

Finalmente, hay que ser concisos en plantear que la filosofía del bien común no es fácil de aplicar, menos aún en un sistema en donde la estructura de los valores democráticos colapsó y la participación como derecho está perdida, en donde se reemplaza la dignidad humana por prácticas nocivas, en donde el derecho a elegir y a ser elegido no existe en la realidad, y en donde cualquier tendencia de cambio activa resistencias y genera tragedias sociales de escala máxima.

No en vano FELBER (2012) plantea que la democracia representativa debe ser efectivamente complementada por la democracia directa y la participativa, en donde el pueblo soberano tiene el derecho práctico a: corregir a sus representantes, iniciar y adoptar leyes, iniciar y adoptar cambios constitucionales, y controlar áreas claves de la economía como los bienes democráticos, entre otros, los recursos naturales, el conocimiento, la libertad de expresión y la dignidad.

\section{Referencias}

FELBER, C. 2012. La economía del bien común. Deusto S.A. Ediciones. Barcelona, España.

OSTROM, E. 2011. El gobierno de los bienes comunes - La evolución de las Instituciones de acción colectiva”. $2^{\text {da }}$. UNAM-CRIM-FCE. Cambridge University Press. 